\title{
Direct electron heating at moderate harmonic number for compact ignition devices.
}

\author{
R. Majeski \\ Princeton Plasma Physics Laboratory, Princeton, N. J. 08543
}

RECEIVED

JUL 151999

\begin{abstract}
Direct electron heating of compact ignition devices by radio-frequency power in the $300-400 \mathrm{MHz}$ range is discussed. The possible advantage of this approach to heating an ignition device, as opposed to resonant heating of an ion population, is the insensitivity to the exact value of the magnitude field. Heating with central power deposition during a toroidal field ramp is therefore possible.
\end{abstract}

\section{INTRODUCTION}

Ion cyclotron resonance heating (ICRH) has been the preferred heating technique for virtually all proposed compact ignition devices. The high magnetic field, high operating density, and small access ports envisioned for these devices preclude electron cyclotron heating or neutral beam injection, with presently available technologies. ICRH, on the other hand, promises central power deposition and strong absorption at high density. However, operating scenarios for these devices often include a requirement for heat input during a toroidal field ramp. For example, in the case of the proposed Ignitor device (1), heating during a ramp from 8 to $13 \mathrm{~T}$ is desirable, in order to freeze the current profile and prevent early sawtoothing, which would expel fusion alphas. A change of $60 \%$ in the toroidal field obviously produces large excursions in the positions of ion cyclotron resonances during the ramp, for a fixed heating frequency. Off-axis, or even edge, power deposition can result. Furthermore, Ignitor is designed for moderately low aspect ratio $(R=132 \mathrm{~cm}, a=47$ $\mathrm{cm}$ ), so that several ion cyclotron layers may be present in the device simultaneously.

If heating at full power for part of the toroidal field ramp, or if heating at reduced power (e.g. alternating between two frequencies) with occasional off-axis deposition is acceptable, then ICRH will be adequate. An ICRH system has been designed for Ignitor (2), and modeling indicates that good heating efficiency would be obtained for centrally located ion resonances. If, on the other hand, full power heating throughout the ramp with continuous central power deposition is necessary, then this would be a difficult requirement for any ICRH system to fulfill.

Direct electron heating, however, is largely insensitive to the magnetic field, if ion resonances can be avoided. Here we discuss the possibility of heating compact ignition devices through fast wave electron heating (FWEH), using the Ignitor device as a design basis.

FWEH PARAMETERS

$400 \mathrm{MHz}$ was chosen as the operating frequency for this study. This frequency locates the second harmonic of the hydrogen cyclotron resonance on-axis 


\section{DISCLAIMER}

This report was prepared as an account of work sponsored by an agency of the United States Government. Neither the United States Government nor any agency thereof, nor any of their employees, make any warranty, express or implied, or assumes any legal liability or responsibility for the accuracy, completeness, or usefulness of any information, apparatus, product, or process disciosed, or represents that its use would not infringe privately owned rights. Reference herein to any specific commercial product, process, or service by trade name, trademark, manufacturer, or otherwise does not necessarily constitute or imply its endorsement, recommendation, or favoring by the United States Government or any agency thereof. The views and opinions of authors expressed herein do not necessarily state or reflect those of the United States Government or any agency thereof. 


\section{DISCLAIMER}

Portions of this document may be illegible in electronic image products. Images are produced from the best available original document. 
at the full operating field of $13 \mathrm{~T}$. The choice of a higher operating frequency would avoid even the $2 \Omega_{\mathrm{H}}$ layer. However, at $400 \mathrm{MHz}$ the lower hybrid resonance occurs at a low density $\left(7 \times 10^{18} \mathrm{~m}^{-3}\right)$ compared to the expected central density of $5-10 \times 10^{20}$ $\mathrm{m}^{-3}$. At higher frequencies (e.g. $700-800 \mathrm{MHz}$ ) the lower hybrid resonance occurs at correspondingly higher density $\left(\sim 3 \times 10^{19} \mathrm{~m}^{-3}\right)$. Excitation of the lower hybrid resonance may therefore be a factor if the operating frequency is increased.

Even though Ignitor is projected to operate at modest electron $\beta$, and therefore the damping decrement per radial wavelength for direct electron heating is modest, the high operating density and relatively high frequency produce a short radial wavelength $\left(\lambda_{\perp} \sim 2-3 \mathrm{~cm}\right)$. As a result, $\left(a / \lambda_{\perp}\right)$ is large, so that the integrated per-pass fast wave electron damping is adequate.

A high parallel wavenumber $\left(30 \mathrm{~m}^{-1}\right)$ was chosen to damp in the bulk electron distribution rather than at high $\mathrm{v}_{\phi}\left(=\omega / \mathrm{k}_{\|}\right) / \mathrm{v}_{\mathrm{Te}}$, since current drive is not expected. The resultant $n_{\|}$is identical to that chosen for the ICRH system design, so the fast wave cutoff density will lie at a similar distance from the antenna in both cases.

\section{MODELING OF FWEH}

The codes used in modeling FWEH were primarily the 1-D codes FELICE (3) and METS (4). In Figure 1 is shown the predicted per-pass damping on electrons and on hydrogen $(1 \%)$ at the $2 \Omega_{\mathrm{H}}$ layer as a function of electron temperature for a central density of $5 \times 10^{20} \mathrm{~m}^{-3}(\mathrm{a})$ and $1 \times 10^{21} \mathrm{~m}^{-3}(\mathrm{~b})$.
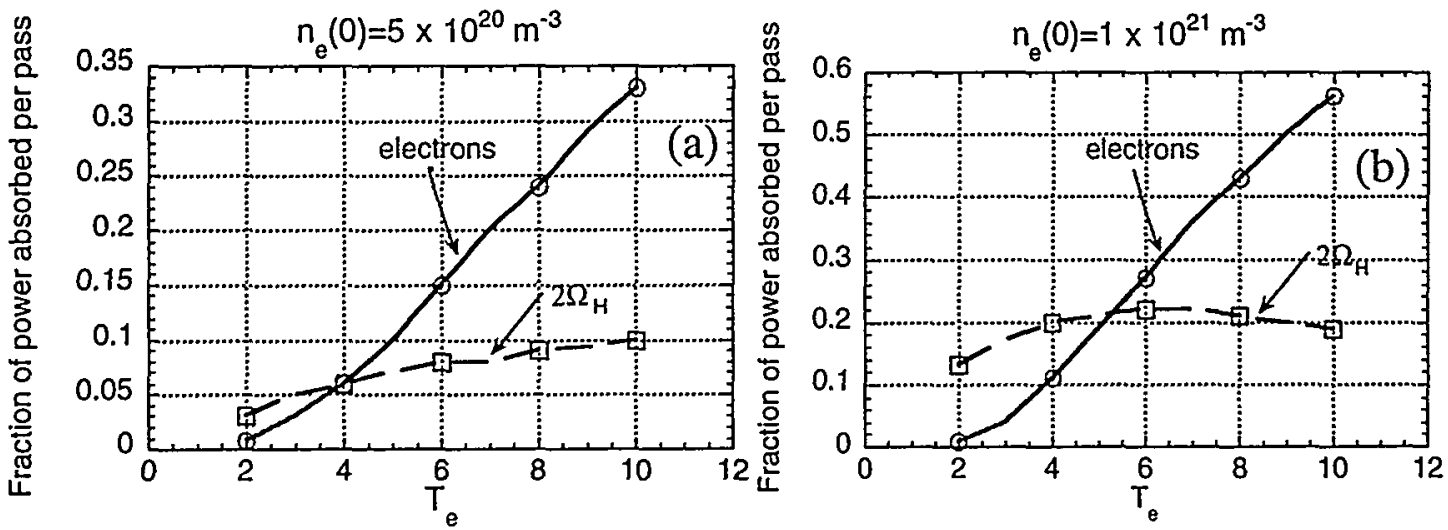

FIGURE 1. $400 \mathrm{MHz}$ fast wave electron absorption as a function of electron temperature for $(a) n_{c}(0)=5 \times 10^{20} \mathrm{~m}^{-3}$, and (b) $n_{e}(0)=1 \times 10^{21} \mathrm{~m}^{-3}$. The modeled density profile was (parabolic) $)^{0.25} \cdot T_{i}=T_{c}$ with profile (parabolic) ${ }^{2}$.

Per-pass absorption is high; $75 \%$ total at the higher density, with approximately $1 / 3$ of the absorbed power deposited on the hydrogen population. Total absorption is adequate at temperatures greater than $5 \mathrm{keV}$. Per - pass absorption at projected operating parameters $(\sim 10 \mathrm{keV})$ is comparable to that predicted for minority ICRH.

Absorption at the $2 \Omega_{H}$ layer is reduced at lower magnetic field, when the resonance is off-axis to the high field side. For fixed plasma parameters, the per-pass 
electron absorption is also increased at lower magnetic field (higher electron $\beta$ ). The effect of operating at lower magnetic field is shown in Figure 2 ( $a$ \& b).
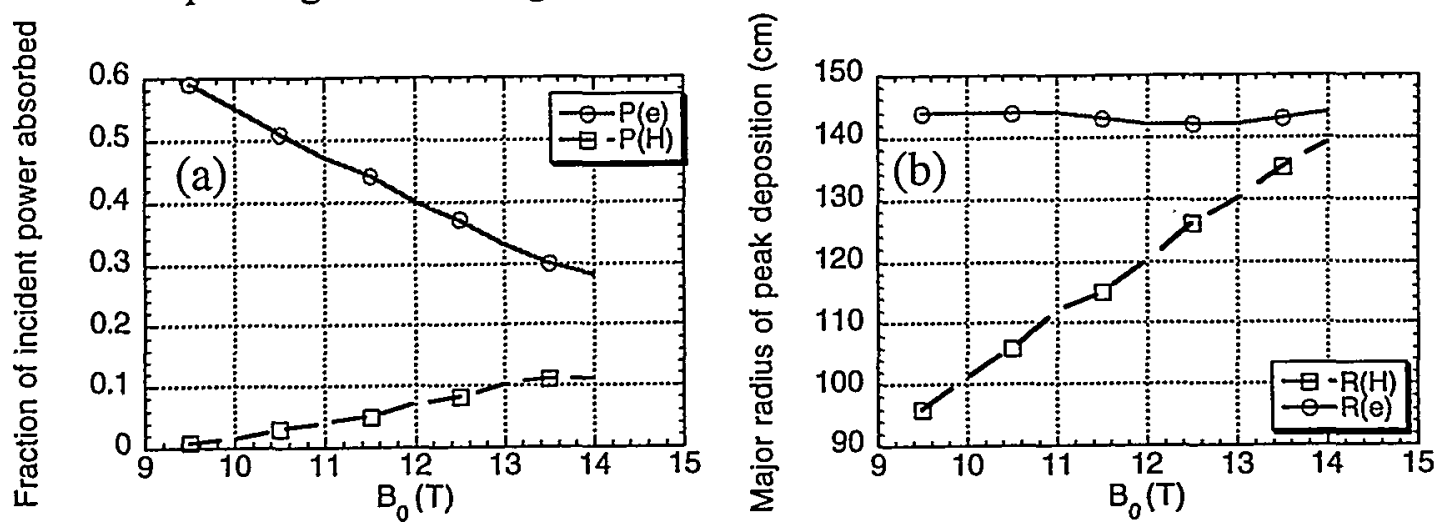

FIGURE 2. Per-pass absorption as a function of magnetic field (a), and redius of power deposition (b).

Note that in the case where the power deposited in the $2 \Omega_{\mathrm{H}}$ layer is at $\mathrm{r} / \mathrm{a}>0.5$, the fraction of power deposited per-pass on the ions is $<5 \%$, whereas $50 \%$ per pass is deposited on-axis in the electrons.

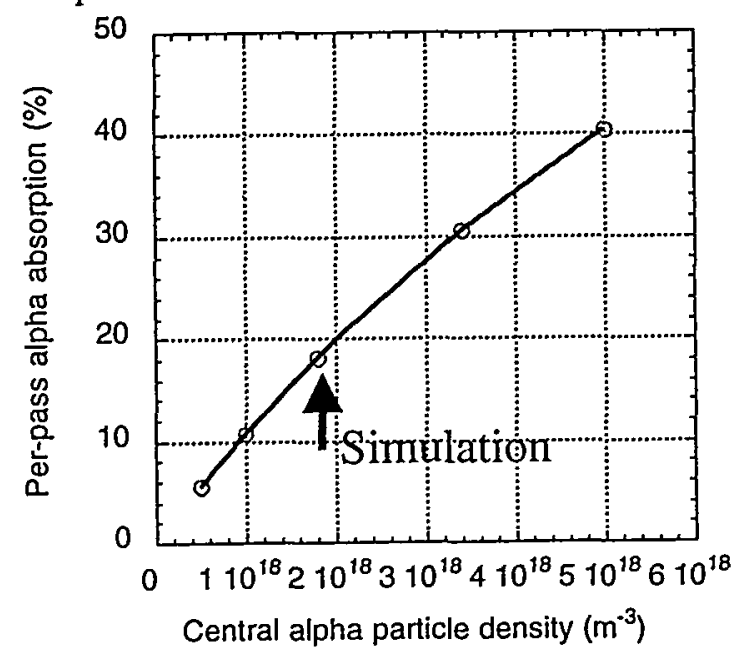

Figure 3. Fast wave alpha particle absorption (per pass) as a function of the fast alpha particle density. The expected alpha population is indicated.

Moderate damping on the alpha particle population, at $4 \Omega_{\alpha}$, is predicted by the METS code. Here the alpha particle population is modeled by an equivalent Maxwellian with a temperature of $800 \mathrm{keV}$. The per-pass damping as a function of the alpha particle density is shown in Figure 3. The expected fast alpha population for Ignitor is indicated. Since the slowingdown time for alphas is very short $(\sim$ $35 \mathrm{msec}$ ) in Ignitor, and the absorbed $\mathrm{RF}$ power is a small fraction of the total alpha power, RF absorption is not expected to have a significant effect on the alpha particle population.

Finally, at the beginning of the toroidal field ramp $(8 \mathrm{~T})$, an electron temperature of a few $\mathrm{keV}$ is sufficient to produce adequate per-pass damping, as shown in Figure 4.

\section{FWEH HARDWARE}

The sources for the fixed frequency $400 \mathrm{MHz}$ system would be $1 \mathrm{MW} \mathrm{CW}$ klystrons which have been developed for particle accelerator applications. Matching 
Figure 4. Per-pass damping as a function of electron temperature, for $8 \mathrm{~T}$ operation and two values of the central density. $T_{c}=T_{j}$.

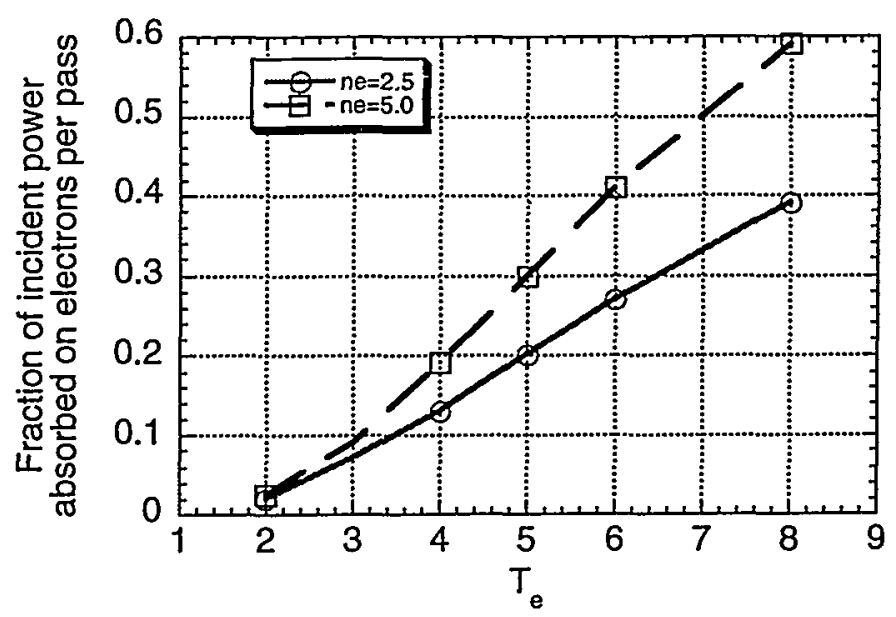

and isolating systems have also been developed by the particle accelerator community. The high frequency and hence short vacuum wavelength are amenable to a folded waveguide launcher.

\section{SUMMARY}

Fast wave electron heating at moderate harmonic number (4-6 $\Omega_{D}$ ) appears to be well suited to compact ignition devices. Such a heating system would provide central power deposition with adequate per-pass absorption at a fixed frequency, regardless of the operating magnetic field. Large toroidal field ramps with full auxiliary heating would be possible, whereas the use of conventional ICRH would require reduced power operation during the ramp, or a shutdown of the RF system during periods when ion cyclotron resonances were located in the edge plasma near the antenna. FWEH therefore appears to be an attractive option for compact ignition devices.

\section{ACKNOWLEDGMENTS}

The author would like to acknowledge Marco Brambilla and Dave Smithe for their kind permission to use FELICE and METS, and Paul Bonoli and Cynthia Phillips for valuable discussions and advice in the use of the codes. Information on the alpha particle population in Ignitor was provided by Linda Sugiyama. Dick Aamodt suggested that a survey of applicable RF heating techniques for Ignitor be undertaken in the first place, and Dale Meade provided encouragement. J. Menard and J. R. Wilson provided valuable insight. This work was supported by the U.S. Department of Energy under Contract No. AC02-76-CH0-3073.

\section{REFERENCES}

(1) B. Coppi, et al., Fusion Technology 21 (1992) 1612.

(2) R. Maggiora, et al., Fusion Eng. and Design 38 (1998) 353.

(3) M. Brambilla, Nucl. Fusion 28 (1988) 549.

(4) D. Smithe, et al., Proc. $12^{\text {th }}$ Top. Conf. on Radio Frequency Power in Plasmas, AIP 403 (1997) 367. 